\title{
Research on Rural E-commerce Cluster Development Trend
}

\author{
Xinyu Nie ${ }^{1, \text { a }}$, Jiguo Zhang ${ }^{1, b}$, Yuqin Lin ${ }^{1, c}$ \\ ${ }^{1}$ College of Business Administration,Hohai University,Changzhou 213022,China. \\ a1508264910@qq.com, b908460934@qq.com, ' $1195871051 @ q q . c o m$
}

Key words: rural e-commerce cluster; trend forecast; comprehensive evaluation; ShaJi

Abstract: This paper uses single index method and comprehensive index method respectively to investigate the development of a typical rural e-commerce industry cluster-ShaJi e-commerce cluster in Jiangsu province and forecasts its development trend by building growth curve models.The result shows that the overall process of e-commerce industry cluster in Shaji during 2006-2014 was on the rise,with a significant increasing trend in the next three years basing on the almost identical tendency of the two evaluation methods.

\section{Introduction}

In recent years, rural e-commerce cluster expands very fast around China, becoming a new engine to promote the growth of rural economy.By 2015,the number of "taobao" village has reached 780,up 269.7\%,distributed in Guangdong,Jiangsu and other 10 areas[1]. Rural e-commerce, as an important measure to promote rural informatization and solve tri-agricultural problem, plays a vital role in the construction of rural economy's transformation and upgrading and social harmony and stability. To ensure its sustainable development, it is necessary to explore a method to evaluate the development level and predict its trend, which can help the local government make support policies and strategies to solve the problems in its developing process.

As a new type of e-commerce cluster form, academics mostly focus on the qualitative analysis of rural e-commerce cluster's cultivation and development pattern, forming reason and construction measures. Till now, there are few about its development level assessment and development trend prediction. From current researches,there has been a mature assessment system of cluster development level and trend prediction,which can provide some reference for research on rural e-commerce cluster.Based on two method,single index evaluation and comprehensive evaluation,scholars have tried to build different kinds of growth curve models to predict cluster development trend.Common growth curve models include exponential curve model[2],Logistic curve model[3],polynomial curve model[4],revised S curve model[5] and so on.This paper uses single index method and comprehensive index method respectively to investigate the development of a typical rural e-commerce industry cluster-ShaJi e-commerce cluster in Jiangsu province and forecasts its development trend by building growth curve models, in order to provide a practical method for the quantitative analysis in rural e-commerce cluster field.

\section{Single index evaluation}

Single index evaluation is a kind of method which selects a specific index as the observation to analyze the development level of industrial cluster.This article chooses e-commerce sales as the observation to measure the development level of e-commerce cluster in Shaji.

Cubic curve model. According to annual data of e-commerce sales, the cubic curve model is the best model among several different models of curve estimation with SPSS(R2=0.972). The regression equation is:

$$
\hat{\mathrm{y}}_{\mathrm{t}}=0.066 t^{3}-0.388 t^{2}+1.021 t-0.711 \quad(t=1,2, \cdots, 9)
$$

To test the fit between data and model, this article uses the method of error analysis. It is defined as follows:absolute error $e_{t}=y_{t}-\hat{y}_{t}$; average error $d_{t}=\left(y_{t}+\hat{y}_{t}\right) / 2$; the rate of absolute error $\frac{\left|e_{t}\right|}{d_{t}}$ and 
MAPE $=\frac{1}{n} \sum_{t=1}^{n} \frac{\left|e_{t}\right|}{d_{t}} * 100 \% \quad y_{t}$ means raw data and ${ }^{\Lambda} y_{t}$ means prediction data.

Seen from table 2, the rate of absolute error of cubic curve model has decreased to 0.0327 in 2014, with a trend reducing gradually and substantially.However,when it comes to MAPE,which is up to $45 \%$,showing a low fitting degree as a whole.

Revised S curve model . In view of limited models SPSS supplies,this paper has tried to build other fitting models and chosen the most suitable one.Based on error analysis results of different kinds of fitting models,revised S curve model has been set up to analyze development trend.Revised $\mathrm{S}$ curve model can be described as: $\mathrm{y}_{\mathrm{t}}=e^{k+a b^{t}}$ (2)

Coefficients in the equation(2)can be calculated as follow:

$\mathrm{b}=\frac{(n-1) \sum_{t=1}^{n-1} Y_{t} \bullet Y_{t+1}-\sum_{t=1}^{n-1} Y \sum_{t=1}^{n-1} Y_{t+1}{ }_{t}}{(n-1) \sum_{t=1}^{n-1} Y^{2}{ }_{t}-\left(\sum_{t=1}^{n-1} Y_{t}\right)^{2}} ; \quad \mathrm{a}=\frac{\mathrm{n} \sum \mathrm{b}^{\mathrm{t}} \bullet Y_{t}-\sum b^{t} \sum Y_{t}}{n \sum b^{2 t}-\left(\sum b^{t}\right)^{2}} ; k=\frac{\sum Y_{t}-a \sum b^{t}}{n}$.

$y_{t} Y_{t} Y_{t}=L n y_{t}$; ; that is to say:

Then the revised $\mathrm{S}$ curve regression equation is:

$\hat{y_{t}}=e^{7.0302-10.7480 \bullet 0.8894^{t}} \quad(\mathrm{t}=1,2 \ldots 9)$

The result of fit testing has shown in table 2. It is obvious that revised S curve model fits better than cubic curve model.Otherwise, MAPE of Revised S curve model is $13 \%$, which is much less than $45 \%$ of cubic curve model. Therefore, choosing revised S curve model to analyze and predict is more suitable in this study.

\section{Comprehensive evaluation}

Comprehensive evaluation can provide a comprehensive picture of industrial cluster development by constructing a multiple index system.Compared with the traditional industrial clusters, e-commerce cluster has a wider scope, a more flexible organization scale more influence factors, which need consider e-commerce's own characteristics when it comes to assessing its development. The theory of $\mathrm{S}$ type curve e-commerce model proposed by the organization for economic co-operation and development (OECD) [6] is regarded as the theoretical basis for further research.Based on that theory,some scholars have built various measurement system of e-commerce development according to different research purposes and the research objects, Such as the e-commerce readiness assessment guidelines proposed by APEC (2006) in order to help the government assess the status of e-commerce ready degree[7], the measure system containing e-commerce transaction scale, infrastructure and the influence on national economy built by Liu Min(2008) giving a wide view of influence factors[8].

Indicators selection and weights determining. Based on the research results of Liu Min,this paper constructs a measure index system(table1) to analyze ShaJi e-commerce industry cluster development,taking data availability and indicator independence into consideration. 
Table1. Indicator system for evaluating rural e-commerce industry development

\begin{tabular}{cccc}
\hline Criteria evaluation & Indicator evaluation & Units & Weight \\
\hline \multirow{2}{*}{ cluster scale index } & e-commerce sales & [billion yuan] & 0.3345 \\
& online retailers & [person] & 0.2313 \\
\hline \multirow{2}{*}{ cluster infrastructure } & logistics company & [number] & 0.1868 \\
level index & fixed line penetration & [kilometer] & 0.0242 \\
& mobile phone penetration & [per hundred] & 0.0003 \\
& annual Electricity Consumption & [ten thousand kW.h] & 0.0298 \\
& housing rate & [\%] & 0.0171 \\
\hline \multirow{2}{*}{ cluster influence } & Gross regional domestic product; & [ten thousand yuan] & 0.0801 \\
degree index & rural per capital net income & [yuan] & 0.0253 \\
& financial gross income & [ten thousand yuan] & 0.0366 \\
\hline
\end{tabular}

This paper uses the entropy weight method to determine the weight of each index. Entropy weight method is a kind of objective structure weight method, mainly based on calculation the degree of index data variation, so it effectively avoid subjective errors and objectively and truly reflect rural e-commerce cluster development level.Main steps are as follows [9]:

(1) Standard processing. Indicators in table 1 are all efficiency indicator, so they can be normalized as:

$$
y_{i}=\frac{x_{i}-\min \left(x_{1}, x_{2}, \cdots, x_{n}\right)}{\max \left(x_{1}, x_{2}, \cdots, x_{n}\right)-\min \left(x_{1}, x_{2}, \cdots, x_{n}\right)}
$$

Where $y_{i}$ presents standardize data.

(2) Calculate the proportion of indicator evaluation. $u_{i j}$ is used to describe the proportion of indicator evaluation called $j$ for the evaluated objective called $i$.

$$
\mathrm{u}_{i j}=\frac{y_{i j}}{\sum_{i=1}^{m} y_{i j}}
$$

(3) Calculate the entropy of indicators. Calculating results show as $E_{n}=\left[e_{1}, e_{2}, \cdots, e_{n}\right]$.The computational formula of single indicator ${ }^{e_{j}}$ is

$$
e_{j}=\frac{1}{\ln m} \sum_{i=1}^{m}\left(-u_{i j} \ln u_{i j}\right)
$$

(4) Calculate entropy weight. The computational formula is

$$
w_{j}=\left(1-e_{j}\right) / \sum_{j=1}^{k}\left(1-e_{j}\right)
$$

(5) Evaluate sustainable development ability of regional e-commerce expressed in SARD. The computational formula is

$$
\operatorname{SARD}_{i}=\sum_{j=1}^{n} w_{j} * y_{i j}
$$

Weight calculated has shown in table1 and SARD results in table 2.

Development trend analysis. According to annual data of SARD, the conic curve model is the best model among several different models of curve estimation with SPSS $\left(\mathrm{R}^{2}=0.990\right)$. The regression equation is: 
$\mathrm{SARD}_{t}=0.009 t^{2}+0.022 t+0.023$

Meanwhile, other growth curve models have been used in this research and the fitting degree of revised $\mathrm{S}$ curve model is best.The revised $\mathrm{S}$ curve regression equation is:

$\operatorname{SARD}_{t}=e^{2.478205-5.71899 \bullet 0.909839^{t}}$

Table 2.Error analysis of different models

\begin{tabular}{|c|c|c|c|c|c|c|c|c|c|c|}
\hline \multirow{3}{*}{ Year } & \multicolumn{5}{|c|}{ Single index evaluation } & \multicolumn{5}{|c|}{ comprehensive evaluation } \\
\hline & & \multicolumn{2}{|c|}{$\begin{array}{l}\text { cubic curve } \\
\text { model }\end{array}$} & \multicolumn{2}{|c|}{$\begin{array}{l}\text { revised S curve } \\
\text { model }\end{array}$} & \multirow{2}{*}{$S A R D_{t}$} & \multicolumn{2}{|c|}{$\begin{array}{l}\text { conic curve } \\
\text { model }\end{array}$} & \multicolumn{2}{|c|}{$\begin{array}{l}\text { revised S curve } \\
\text { model }\end{array}$} \\
\hline & & $\begin{array}{l}\Lambda \\
y_{\mathrm{t}}\end{array}$ & $\frac{\left|e_{t}\right|}{d_{t}}$ & $\begin{array}{c}\Lambda \\
y_{\mathrm{t}}\end{array}$ & $\frac{\left|e_{t}\right|}{d_{t}}$ & & $S A R D_{\mathrm{t}}$ & $\frac{\left|e_{t}\right|}{d_{t}}$ & $\stackrel{\Lambda}{S A R D_{\mathrm{t}}}$ & $\frac{\left|e_{t}\right|}{d_{t}}$ \\
\hline 2006 & 0.089 & -0.012 & 2.6233 & 0.08 & 0.1065 & 0.072 & 0.054 & 0.284 & 0.066 & 0.091 \\
\hline 2007 & 23 & 0.307 & 0.2868 & 0.23 & 0 & 0.095 & 0.103 & 0.08 & 0.105 & 0.097 \\
\hline 2008 & 0.4 & 0.642 & 0.4645 & 0.588 & 0.3806 & 0.123 & 0.17 & 0.318 & 0.161 & 0.262 \\
\hline 2009 & 1.7 & 1.389 & 0.2013 & 1.358 & 0.2237 & 0.279 & 0.255 & 0.09 & 0.237 & 0.164 \\
\hline 2010 & 3.1 & 2.944 & 0.0516 & 2.858 & 0.0812 & 0.391 & 0.358 & 0.088 & 0.337 & 0.148 \\
\hline 2011 & 5 & 5.703 & 0.1314 & 5.538 & 0.1021 & 0.514 & 0.479 & 0.07 & 0.465 & 0.1 \\
\hline 2012 & 12 & 10.062 & 0.1757 & 9.975 & 0.1843 & 0.615 & 0.618 & 0.004 & 0.623 & 0.012 \\
\hline 2013 & 15 & 16.417 & 0.0902 & 16.834 & 0.1152 & 0.741 & 0.775 & 0.045 & 0.813 & 0.093 \\
\hline 2014 & 26 & 25.164 & 0.0327 & 26.811 & 0.0307 & 0.996 & 0.95 & 0.047 & 1.035 & 0.039 \\
\hline
\end{tabular}

The error analysis of conic curve model and revised S curve model is shown in table2.Seen from it, the difference of error analysis between two kinds of growths models(SARD) is little,so as each MAPE,which means both two curve models can well simulate the development trend of historical data. To improve the accuracy of predicting results, this article take the average of the two kinds of models as the final results when predicting.

\section{Summary}

Both single index evaluation and comprehensive index evaluation have been used in this paper to investigate the development of a typical rural e-commerce industry cluster-ShaJi e-commerce cluster in Jiangsu province.Meanwhile,different growth curve models have been established to simulate historical data and forecast trend. To compare the evaluation trend results, figure1( SARD expressed by red square;e-commerce sales expressed by blue circle) is painted whose time sequence data come from two methods. As can be seen from the figure 1, the results of the two evaluation methods have roughly the same change trend, in a state of continuous rising, which shows ShaJi e-commerce cluster development is in health. 


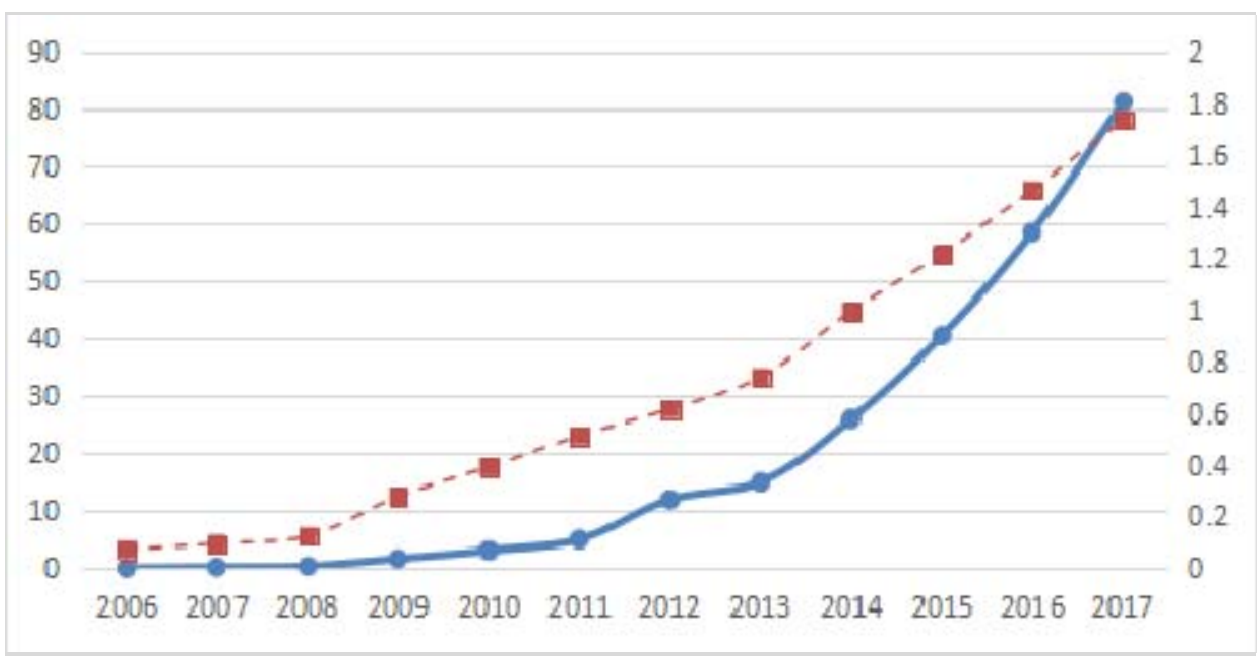

Figture1. Compare of two evaluation methods

\section{Acknowledgements}

This work was financially supported by the Zhejiang Province Statistical Key Research Program(2015-26) and Ordinary University Graduate Student Scientific Research Innovation Projects of Jiangsu Province(KYLX15_0522).

\section{References}

[1]Information on http://www.askci.com/news/chanye/2015/12/25/161620cd1y.shtml.

[2]Peng Jing-dong.Development Trend Forecast of High-tech Industries in Hunan Province(in Chinese).Economic Research Guide,2009,29:40-42.

[3]Liu Manfeng,Wei Wenchao.The Ecological Symbiosis Stability Analysis of Industrial Clusters Based on Extended Logistic Model(in Chinese).Science and Technology Management Research,2015,8:121-125.

[4]Zhao Liping. A research on curve prediction model of product life cycle(in Chinese).Business economy,2013,6:27-29.

[5]Chang Zheng.Life Cycle Model of DCI and Identification of Developmental Stage(in Chinese).Journal of Beijing University of Posts and Telecommunications ( Social Sciences Edition),2012,1:67-73.

[6]OECD. Committee for Information Computer and Communications Policy [R]. Measuring Electronic Commerce. Paris,1999.

[7]Chen,Andrew NK,SagnikaSen,and Benjamin Shao.Strategies for effective Web services adoption for dynamic e-bussinesses.Decision Support Systems42.2(2006):789-809

[8]Liu Min.Research on Indicator System for Measuring E- commerce(in Chinese).Statistics\& Information Forum,2008,07:20-28.

[9]Zhang Jiguo, Vijay P Singh. Informational entropy theory and Application(in Chinese).China WaterPower Press, Beijing, 2012, 79-81. 